\title{
ВЛИЯНИЕ ПОЛИТИЧЕСКИХ РАЗМЕЖЕВАНИЙ НА ПАРТИЙНЫЕ СИСТЕМЫ ПОСТСОВЕТСКИХ СТРАН БАЛТИИ
}

Аннотация: Объектом исследования являются политические размежевания в постсоветских странах Балтии. Предметом выступают закономерности влияния политических размежеваний на развитие партийных систем этих молодых демократий. Автор рассматривает влияние политических размежеваний на основе анализа четырех политических расколов, которые в той или иной мере отражались в партийной конкуренции в период постсоветского развития балтийских государств. Речь идет, во-первых, о расколе по идеологической линии «правые-левые»; во-вторых, расколе по религиозной линии «католицизм-светскость»; в-третьих, расколе по поселенческой линии «город-село» и, наконец, в-четвертых, расколе по этнической линии «титульный этнос-русскоязычное население». Теоретической основой исследования являются кониепты политических размежеваний С. Липсета, С. Роккана и Дж. Сартори о влиянии поселенческих, классовых и религиозных расколов на формирование современных партийных систем. Для выявления кросс-национальной специфики, а также изучения особенностей влияния политических размежеваний на развитие партийных систем используется сравнительный метод. Основным выводом проведенного исследования является эмпирическое подтверждение гипотезы о том, что в условиях становления новых демократий влияние идейно-ценностных политических расколов на развитие партийной системы уменьшаются по мере того, как общество теряет свои переходные характеристики и формирует более стабильные профессиональные и социально-классовые интересы. Процесс влияния структурных и политических размежеваний на партийную систему в постсоветских странах Балтии условно можно разделить на два этапа. На первом этапе (1990-е гг.) в условиях стремительной трансформации социальной структуры и отсутствия четко выраженных общественных интересов электоральные расколь формировали политические элиты на основе конкуренции идеологических платформ. В этот период доминируюшими размежеваниями оказались политические ценности по линии «коммунизм-антикоммунизм», «рынок-градуализм», «европейская интеграция - пророссийское сближение» и т. n. На втором этапе (2000-е г2.) кроме инициированных элитами политических предложений более значимую роль стали играть структурные расколь и электоральный спрос, обусловленные объективными размежеваниями соичума, принимающего более рельефные и устойчивые структурные характеристики. Поэтому в рамках последних электоральных ичиклов все большую роль играют расколь не по линии политических иенностей и идеологий, а размежевания поселенческого (город-село) и этнического характера.

Ключевые слова: Политические размежевания, партийная система, политические ценности, политические партии, идеологии, этносы, нации, страны Балтии, политика, демократия.

Abstract: In this research the author examines the effect of political delimitations based on the analysis of the four political breakups, which in one or another way reflected in the competitiveness of the parties throughout the post-Soviet development of the Baltic states. The breakups were first and foremost in ideology (left-right), then religious background (Catholicismsecularism), division by residency (city-town), and division by the ethnicity (titular ethnos-Russian heritage population). The main conclusion of the conducted research is the empirical confirmation of the hypothesis that in the establishment of the new democracies the influence of the ideological-value political breakups upon the development of the party system diminishes as the society rids itself of the transitional characteristics and forms the more stable professional and socio-class interests. The process of the influence of the structural and political delimitations upon the party systems in the post-Soviet Baltic states can be divided into two stages: 1990's - under the rapid transformation of the social structure and lack of clearly expressed public interests, the electoral splits were formed by the political elites based on the competition between ideological platforms (communism-anti-communism, market-gradualism, European integration-pro-Russian movement); 2000's - in addition to the political proposals initiated by the elites, a more noticeable role began to be played by the structural splits and electoral demand, thus within the framework of the most recent electoral cycles the biggest role is played not by the divisions of political values and ideologies, but a divisions of residency (city-town) and ethnic nature.

Keywords: Political delimitations, Party system, Political values, Political party, Ideology, Ethnos, Nations, Baltic states, Policy, Democracy. 
DOI: $10.7256 / 1811-9018.2015 .6 .15529$

При цитировании этой статьи сноска на доі обязательна

\section{Право и политика $6(186) \cdot 2015$}

$\mathrm{P}$ аспад Советского Союза в начале 1990-х гг. положил начало трансформации постсоветских обществ. Руководство почти всех бывших советских республик провозгласили своей целью построение демократии, рыночной экономической системы и формирование национальной государственности [11]. Хотя конечные исходы во многих странах бывшего СССР оказались различными, ряду новых государств действительно удалось добиться поставленных целей. В этом ряду могут рассматриваться страны Балтии, которые к концу ХХ столетия по оценкам ведущих аналитических центров достигли статуса «новых демократий» [8].

Для политической науки постсоветский опыт развития политических систем Балтии ценен возможностью анализа формирования новых политических институтов и конкретных детерминант, определяющих характер их трансформаций. В частности, это позволяет провести тестирование ранее выдвинутых гипотез о роли социентальных и политических размежеваний в становлении партийных систем в новых демократиях. В данной статье проведен анализ политических размежеваний в постсоветских странах Балтии с целью изучения их влияния на электоральное поведение и партийную конкуренцию.

Под политическими размежеваниями принято понимать электоральные расколы, обусловленные социальной структурой. Эти расколы могут стать основанием для партийного размежевания и определить контуры политической конкуренции. Не каждое социальное размежевание отражается в политическом поле, поскольку для этого необходим политический субъект, способный артикулировать и политизировать существующую общественную дифференциацию. Кроме того, следует различать такие феномены как «политические размежевания» и «проблемные электоральные расколы». В первом случае имеются в виду долговременные, обусловленные социальной структурой устойчивые разнонаправленные политические предпочтения электората. Если речь идет о ситуативном электоральном расколе, вызванным конкретной проблемной ситуацией и исчезающим сразу после ее разрешения, то в данном случае корректнее говорить о электоральном расколе, не имеющим фундаментальных социальных основ.

В современной политической теории можно выделить два основных подхода, дающих понимание взаимосвязям между социальными размежеваниями и характером партийных систем. Истоки первого восходят к классическим работам С. Липсета и С. Роккана, ко- торые показали, что современные партийные системы стран Западной Европы стали отражением социальных расколов, в ряду которых они выделили размежевания по линии «центр-периферия», «город-село» и «рабочие-собственники» [10]. Дж. Сартори можно признать родоначальником второго подхода, который указал, что политические субъекты могут не только артикулировать существующие социальные размежевания, но и сами конструировать расколы, формируя политическую повестку для электората [12].

Можно предположить, что в новых демократиях на начальном этапе трансформационных процессов, когда общество стремительно меняет свои базовые структурные характеристики, политические элиты могут достаточно произвольно формировать идеологические установки независимо от объективных социальных размежеваний. Это возможно потому, что в силу переходного состояния социума четкие общественные запросы и интересы просто не могут сформироваться. На втором этапе, когда трансформация социальных структур приходит к своему завершению и объективные расколы приобретают рельефность, можно ожидать иное направление взаимосвязей, когда именно социальные расколы становятся основанием для партийного строительства и стратегий основных политических субъектов.

В данной статье эта гипотеза на основе анализа постсоветского политического развития Эстонии, Латвии и Литвы рассматривается сквозь призму влияния на развитие партийных систем четырех типов политических расколов: 1) по идеологической линии «правые-левые»; 2) по религиозной линии «католицизмсветскость»; 3) по поселенческой линии «город-село»; 4) по этнической линии «титульный этнос-русскоязычное население». Первые два раскола можно отнести к разряду идейно-ценностных, которые в целом менее зависимы от объективных социальных структур и поэтому могут выступать ресурсами для элит в плане формирования последними избирательных платформ и политических предложений для электората. В этом смысле эти факторы выступают независимыми от избирателей ресурсами, используя которые элиты могут искусственно формировать политическую повестку и стимулировать электоральные расколы. Поселенческие и этнические расколы носят структурный характер и менее подвержены искусственным манипуляциям со стороны политиков. Отражение этих расколов в партийной системе может говорить о том, что спрос избирателей снизу становится более значимым фактором, чем предложения со стороны элит. 
В течении первого десятилетия постсоветского развития в странах Балтии главным политическим размежеванием выступала идеологическая борьба между прозападными националистическими силами либерального толка и левыми экс-коммунистическими партиями. Так, например, в Литве основной линией политических баталий были идеологические споры между наследницей «Саюдиса» партией «Союз Отечества» (Консерваторы Литвы) и бывшими коммунистами, объединившимися в «Демократическую партию труда Литвы» (ДПТЛ). Идеологический раскол между правыми и левыми, однако, уже к концу 1990-х гг. перестал быть актуальным. Пророссийская или антироссийская риторика лидеров партий, которая приносила значимые электоральные дивиденды в начале 1990- х гг., начала давать сбои на рубеже веков. Это показали парламентские выборы 2000 г., на которых партия «Союз Отчества» получила только 8,62 \% поддержки избирателей, против результата $30 \%$ в предыдущей избирательной кампании 1996 г. [5, с. 183-184]. Равным образом левые силы в виде ДПТЛ в период 2002-2004 гг. сократили свою электоральную поддержку с $31 \%$ до $14 \%$ [9, с. 283]. Политическая повестка, конструированная политическими элитами и основанная на противопоставлении идеологических ценностей по линии «либерализм-коммунизм», перестала отвечать политическим запросам электората.

Значительно меньшую роль в электоральных процессах современных стран Балтии играет размежевание религиозного характера. Хотя в начале ХХ в. религиозный раскол в балтийских странах был достаточно значимым в силу влияния католической церкви и христианско-демократические партии являлись влиятельными политическими силами, коммунистический период привел к существенному ограничению религиозного фактора в политике рассматриваемых случаев. Тем не менее, в первые годы постсоветской независимости в странах Балтии (исключая Эстонию) наблюдался рост популярности христианских партий, которые получили электоральную поддержку в силу своей антикоммунистической направленности. Так, например, в Литве партия «Литовский Христианский Демократический Союз» на парламентских выборах 1992 г. получила $12,6 \%$ голосов избирателей. В Латвии «Христианскодемократический союз» на парламентских выборах 1993 г. заручился поддержкой 5\% избирателей. Однако в дальнейшем артикуляция религиозных ценностей не приносила значимых электоральных результатов и христианские партии во всех балтийских государствах исчезли с политической арены.
Таким образом, можно сделать вывод, что в анализируемых случаях религиозный фактор оказался лишь ситуативным и краткосрочным расколом, который не переродился в устойчивое и долговременное размежевание. И хотя ряд консервативных партий, ориентирующихся на сельское население, включает в свои программы христианские католические ценности, в целом религиозное размежевание не оказывает существенного влияния на развитие партийных систем балтийских государств.

Более долговременное размежевание в новых постсоветских демократиях связано с расколом по линии «город-село». Во многом оно накладывается на отношение электората к рыночным реформам, которые создают разным поселенческим группам как выгоды, так и издержки. Общий курс на модернизацию и либерализацию экономических отношений создал больше возможностей для горожан, в то время как сельские жители и собственники агробизнеса усматривают в рынке угрозу своему благосостоянию и склонны поддерживать более консервативную политику протекционизма. Действительно, рыночные реформы существенно расширили инвестиционную привлекательность стран Балтии. Однако сельские жители получили от этого гораздо более скромные выгоды, чем города. Так, например, в Литве три крупнейших города (Вильнюс, Каунас и Клайпеда) к 2002 г. аккумулировали свыше $80 \%$ всех иностранных инвестиций [9]. Рост безработицы в ходе экономических реформ затронул село гораздо в большей степени, чем города. Это привело к сокращению сельских жителей и существенному уменьшению аграрного производства в общей структуре ВВП. Даже в аграрной Литве доля сельского производства за десять лет постсоветских реформ сократилось с $21,1 \%$ до 5,9\% [9, с. 283].

Накануне постсоветских трансформаций сельские жители в странах Балтии составляли около $30 \%$ всего населения. Направление экономических реформ вызвало неприятие этого слоя населения и составило электоральную базу консервативных правых партий, которые, вступая в разного рода коалиции и эволюционируя, тем не менее, продолжают играть определенную роль в политическом ландшафте балтийских государств. В Эстонии эту нишу последовательно сменяя друг друга занимают такие партии как «Союз аграриев» (получила 5\% на парламентских выборах 1995 г.), «Эстонский аграрный союз» (получила 7\% на парламентских выборах 1999 г.), «Народный союз Эстонии» (получила 13\% на парламентских выборах 2003 г. и 7\% на выборах 2007 г.), «Консервативная народная партия Эстонии» (получила 8\% на парламентских выборах 2015 г.) [2]. 
DOI: $10.7256 / 1811-9018.2015 .6 .15529$

При цитировании этой статьи сноска на доі обязательна

\section{Право и политика $6(186) \cdot 2015$}

В Латвии аграрным партиям также удается мобилизовать своих избирателей и добиваться электоральных побед. Так, на парламентских выборах 1993 г. «Крестьянский союз Латвии» получил почти 11\% поддержки избирателей, что являлось третьим результатом в списке конкурирующих партий. На следующих выбоpax 1995 г. партия сократила уровень своей поддержки до 6,4\%. Выборы 1998 г. оказались для латвийских аграриев провальными. «Крестьянский союз Латвии» набрал только $2,5 \%$ голосов и не получил мест в легислатуре. Однако после партийного реформирования и объединения с «Латвийской зеленой партией» аграрии на выборах 2002 г. смогли вновь вернуться в парламент в рамках партии «Союз зеленных и крестьян», получив 9,4\% поддержки электората. Следующие выборы 2006 г. оказались для этой партии как никогда успешными. «Союз зеленных и крестьян» получил второй результат, заручившись поддержкой почти $17 \%$ избирателей. По результатам выборов 2010 г. партия сохранила и даже увеличила свое представительство до 19\% электоральной поддержки. Похожий результат в 19,5\% партия показала и на последних парламентских выборах 2014 г. [1].

В Литве первой партией, которая явно артикулировала интересы сельских жителей, стала «Литовская крестьянская партия», созданная в середине 1990-х гг. На парламентских выборах 2000 г. партия получила 4\% поддержки избирателей и впервые стала представлена в легислатуре. На следующих выборах 2004 г., «Литовская крестьянская партия» объединилась с партией «Новая демократия» и увеличила свой успех до 6,6\% [3]. Последние выборы 2008 и 2012 гг. оказались для литовских аграриев неудачными. Тем не менее, говорить о исчезновении социального размежевания между городом и селом, как представляется, явно преждевременно.

Таким образом, хотя во всех балтийских странах сельский электорат не представляет большинства и аграрные партии не являются фаворитами электоральных баталий, они, тем не менее, способны артикулировать существующие поселенческие расколы и, опираясь на них, вносить изменения в форматирование партийной системы.

Куда более существенным и долговременным структурным размежеванием является фактор, связанный с этническим измерением балтийских социумов. Это в наибольшей степени справедливо для Латвии и Эстонии, чем для Литвы. Накануне постсоветских трансформаций в Латвии и Эстонии доля русскоязычного населения была очень значительной. В Латвии этнические латвийцы составляли только $52 \%$ жителей, а в Эстонии доля титульного этноса равнялась $62 \%$. В Литве этнический раскол был менее значительным, поскольку литовцы в советский период сохранили свое численное доминирование на уровне $80 \%$ [7, с. 331-341]. Разная этническая композиция балтийских стран обусловили дифференциацию в выборе национальной политики этих государств, что нашло отражение в электоральных процессах. В Латвии и Эстонии были приняты законы о гражданстве, которые существенно ограничили русскоязычное население в политических правах [6]. Поэтому, несмотря на объективный раскол по этнической линии, он не всегда отражался в партийной системе. Так, в Эстонии, несмотря на формирование «Русской партии Эстонии» и других политических организаций, активно артикулировавших интересы русскоязычного населения, данные политические силы не могли добиться электоральных успехов в силу отсечения от избирательного процесса их потенциального электората. Аналогичным образом в Латвии, созданная в 1993 г. «Русская партия Латвии», не смогла добиться прохождения в национальную ассамблею за весь период постсоветского развития [1].

Вместе с тем, нельзя сказать, что этнический фактор совсем не играет роли в электоральных процессах балтийских государств. Спустя 15 лет постсоветского развития значительное количество славянского населения получили статус граждан, пройдя процедуру натурализации. Это увеличило значение «русского фактора» в электоральных процессах и ряд партий эффективно стали использовать его. Так, осознав невозможность победы на основе узкой этнической тематики, в 2005 г. в Латвии была создано партийное объединение «Центр согласия», которое стало артикулировать «русский вопрос» в рамках более широкой политической повестки, чем привлекло славянское население и добилось от них существенной электоральной поддержки. Уже на парламентских выборах 2006 г. это принесло электоральные успехи, когда «Центр согласия» получило 14,4\% голосов избирателей и 17 мест в легислатуре [1]. На следующих выборах Сейма 2010 г. «Центр согласия» увеличил свой результат, заняв второе место и получив $26,04 \%$ голосов (29 мандатов). Наилучших результатов партийное объединение добилось в Латгалии (45,59 \%) и Риге (38,96 \%). На досрочных выборах в сейм 2011 года объединение «Центр согласия» заняло первое место, набрав 29,5\% голосов [1]. Последние парламентские выборы 2014 г. подтвердили лидерство партийного объединения «Центр согласия», которое по итогам избирательной кампании получило 28,36\% голосов и 31 депутатское место. 
Еще более внушительные результаты «Центр согласия» получает на муниципальных выборах. Так, по результатам выборов легислатуры Риги в 2009 г. «Центр согласия» получил рекордные 26 из 60 депутатских мест. В том же году лидер партийной организации Нил Ушаков - был избран мэром столицы Латвии и удерживает этот пост за собой до сих пор [1].

В Литве также этническим партиям более успешно удается выступать на муниципальной политической арене, чем в общенациональном масштабе. Так, политические партии, артикулирующие интересы компактно проживающих поляков добились электорального превосходства в Вильнюсе и с 1997 г. доминируют в легислатуре столичного муниципалитета [4].

Анализ основных постсоветских расколов и степени их отражения на уровне политической конкуренции и партийной системы в странах Балтии позволяет сделать следующие выводы.

Эмпирические данные в виде электоральной статистики постсоветских стран Балтии в целом подтверждают гипотезу о том, что в условиях радикальных социальных трансформаций и становления новых демократий идейно-ценностные политические расколы уменьшают свое влияние по мере того, как общество теряет свои переходные характеристики и формирует более стабильные профессиональные и социально-классовые старты. С этого времени на электоральные процессы и партийную систему более существенное влияние начинают оказывать факторы структурного порядка в виде поселенческого или этнического расколов.
Таким образом, процесс влияния структурных и политических размежеваний на партийную систему в постсоветских странах Балтии условно можно разделить на два этапа. На первом этапе (1990-е гг.) в условиях стремительной трансформации социальной структуры и отсутствия четко выраженных общественных интересов электоральные расколы формировали политические элиты на основе конкуренции идеологических платформ. В этот период доминирующими размежеваниями оказались политические ценности по линии «коммунизм-антикоммунизм», «рынок-градуализм», «европейская интеграция - пророссийское сближение» и т. п. На втором этапе (2000-е гг.) кроме инициированных элитами политических предложений более значимую роль стали играть структурные расколы и электоральный спрос, обусловленные объективными размежеваниями социума, принимающего более рельефные и устойчивые структурные характеристики. Политическая повестка старой генерации элит, основанная на противостоянии правых и левых идеологических ценностей, стала уходить в прошлое. Новое поколение политиков вынуждены искать новые темы для электоральной мобилизации и уже не столько формировать собственные политические платформы, сколько аккумулировать уже существующий электоральный спрос, который формируется на основе объективных социальных размежеваний. Поэтому в рамках последних электоральных циклов все большую роль играют расколы не по линии политических ценностей и идеологий, а размежевания поселенческого (городсело) и этнического характера.

\section{Библиография:}

1. Выборы во всем мире. Электоральная свобода и общественный прогресс. / сост. А. А. Танин-Львов. М.: РОССПЭН, 2001. 1112 c.

2. Кынев А. В., Любарев А. Е. Партии и выборы в современной России: Эволюция и деволюция. М.: Фонд «Либеральная миссия», Новое литературное обозрение, 2011. 792 с.

3. Патнэм Р. Чтобы демократия сработала. М.: Ad Marginem, 1996. 287 c.

4. Патрушев С.В., Айвазова С.Г., Кертман и др. Доверие, гражданское действие, политика: опыт «старых» и «новых» демократий [Электронный документ]: URL: http:/www.civisbook.ru/files/File/Doverie_gragdanskoe\%20dejstvie.pdf (дата обращения: 05.01.2015).

5. Dalton R. Citizen Politics: Public Opinion and Political Parties in Advanced Industrial Democracies. Chatham, NJ: Chatham House, 1996. 345 p.

6. Easton D. A Re-assessment of the Concept of Political Support // British Journal of Political Science. 1975. № 5. P. $435-457$.

7. Freedom in the World 2014 // Официальный сайт Freedom House [Электронный ресурc] URL: https://freedomhouse.org/report/ freedom-world/freedom-world-2014 (дата обращения: 12.11.2014).

8. Klingemann H. - D. Mapping Political Support in the 1990s: A Global Analysis // Critical Citizens: Global Support for Democratic Governance. 1999. P. 31-56.

9. New Baltic Barometer Surveys [Электронный документ]: URL: http://www.balticvoices.org/nbb/surveys.php (дата обращения: 22.11.2014).

10. Steen A. Accessioning Liberal Compliance? Baltic Elites and Ethnic Politics under new International Conditions // International Journal on Minority and Group Rights. 2006. Vol. 13. № 23. P. 187207. 
DOI: $10.7256 / 1811-9018.2015 .6 .15529$

При цитировании этой статьи сноска на dоі обязательна

\section{Право и политика $6(186) \cdot 2015$}

11. Я Яалова Э.Н. Национализм стран Балтии в сравнительной перспективе // Политика и Общество. - 2015. - 1. - С. 24 - 29. DOI: 10.7256/1812-8696.2015.1.14086.

12. Ямалова Э.Н. Политическое представительство и проблемы обратной связи в новых демократиях: опыт постсоветской Литвы // Политика и Общество. - 2015. - 4. - С. 514 - 521. DOI: 10.7256/1812-8696.2015.4.14969.

\section{References (transliterated):}

1. Kynev A. V., Lyubarev A. E. Partii i vybory v sovremennoi Rossii: Evolyutsiya i devolyutsiya. M.: Fond «Liberal'naya missiya», Novoe literaturnoe obozrenie, 2011. $792 \mathrm{~s}$.

2. Patnem R. Chtoby demokratiya srabotala. M.: Ad Marginem, 1996. $287 \mathrm{~s}$.

3. Patrushev S.V., Aivazova S.G., Kertman i dr. Doverie, grazhdanskoe deistvie, politika: opyt «starykh» i «novykh» demokratii [Elektronnyi dokument]: URL: http://www.civisbook.ru/files/File/Doverie_gragdanskoe\%20dejstvie.pdf (data obrashcheniya: 05.01.2015).

4. Dalton R. Citizen Politics: Public Opinion and Political Parties in Advanced Industrial Democracies. Chatham, NJ: Chatham House, 1996. 345 p.

5. Easton D. A Re-assessment of the Concept of Political Support // British Journal of Political Science. 1975. № 5. P. $435-457$.

6. Klingemann H. - D. Mapping Political Support in the 1990s: A Global Analysis // Critical Citizens: Global Support for Democratic Governance. 1999. P. 31-56.

7. Steen A. Accessioning Liberal Compliance? Baltic Elites and Ethnic Politics under new International Conditions // International Journal on Minority and Group Rights. 2006. Vol. 13. № 23. P. 187207.

8. Yamalova E.N. Natsionalizm stran Baltii v sravnitel'noi perspektive // Politika i Obshchestvo. - 2015. - 1. - C. 24 - 29. DOI: 10.7256/1812-8696.2015.1.14086.

9. Yamalova E.N. Politicheskoe predstavitel'stvo i problemy obratnoi svyazi v novykh demokratiyakh: opyt postsovetskoi Litvy // Politika i Obshchestvo. - 2015. - 4. - C. 514 - 521. DOI: 10.7256/1812-8696.2015.4.14969. 